\title{
Repeat Measurement of Cervical Length in Women with Threatened Preterm Labor
}

\section{Wiederholung der Zervixlängenmessung in Frauen mit drohender Frühgeburt}

Authors

Affiliations
P. Wagner $^{1}$, J. Sonek ${ }^{2,3}$, M. Heidemeyer ${ }^{1}$, M. Schmid ${ }^{4}$, H. Abele ${ }^{1}$, M. Hoopmann ${ }^{1}$, K. O. Kagan ${ }^{1}$

${ }^{1}$ Department of Obstetrics and Gynaecology, University of Tübingen, Tübingen, Germany

2 Fetal Medicine Foundation USA, Dayton, OH, USA

${ }^{3}$ Division of Maternal Fetal Medicine, Wright State University, Dayton, OH, USA

${ }^{4}$ Department of Obstetrics and Feto-maternal Medicine, Medical University of Vienna, Vienna, Austria
Key words

- labor

- cervical length

- ultrasonography

- preterm delivery

Schlüsselwörter

- Wehen

- Zervixlänge

- Sonografie

- Frühgeburt

\section{received $\quad 10.12 .2015$ \\ revised 1.3.2016 \\ accepted 2.3.2016}

Bibliography

DOI http://dx.doi.org/

10.1055/s-0042-104282

Geburtsh Frauenheilk 2016; 76:

779-784 @ Georg Thieme

Verlag KG Stuttgart · New York .

ISSN 0016-5751

\section{Correspondence}

Prof. Dr. Karl Oliver Kagan

University of Tübingen

Calwerstraße 7

72076 Tübingen

KOKagan@gmx.de

\section{Abstract}

$\nabla$

Objective: To examine the value of a repeat measurement some days after the first cervical length measurement done at the time of preterm contractions.

Study Design: Retrospective study involving women with singleton pregnancies who presented with preterm contractions at 24 to $33+6$ weeks of gestation. The cervical length was measured at the time of presentation and some days afterwards.

Results: The study population consisted of 17 cases with a preterm delivery within 14 days and 288 uneventful pregnancies. Univariate logistic regression analysis indicated a significant correlation between delivery within 14 days and both, the first and second cervical length measurements as well as the difference between the two measurements. Up to a false positive rate of $20 \%$, ROC curve analysis showed an improved detection rate for preterm delivery by inluding both measurements. At a false positive rate of $10 \%$ which corresponds to a first and second cervical length of 10 and $9 \mathrm{~mm}$ - the detection rate was $17.6 \%$ with the first cervical length measurement, $47.0 \%$ with the second and $52.9 \%$ if the difference between both measurements was added.

Conclusion: Our results indicate that in women with symptoms of preterm labor it is worth to repeat the measurement some days later and to take into account the difference between both measurements.

\section{Zusammenfassung $\nabla$}

Ziel: Ziel der Studie war es, bei Patientinnen mit vorzeitiger Wehentätigkeit den Nutzen einer wiederholten Messung der Zervixlänge zu prüfen.

Design der Studie: Retrospektive Studie bei Frauen mit Einlingsschwangerschaften, die sich zwischen der $24+0$ und $33+6$ SSW wegen vorzeitiger Wehentätigkeit vorstellten. Die Zervixlänge wurde bei der Erstvorstellung sowie einige Tage danach gemessen.

Ergebnisse: Untersucht wurden 17 Patientinnen, die innerhalb von 14 Tagen nach Vorstellung vorzeitig entbanden, sowie 288 Frauen mit komplikationslosen Schwangerschaften. Bei der univariaten logistischen Regressionsanalyse zeigte sich eine signifikante Korrelation zwischen vorzeitiger Entbindung innerhalb von 14 Tagen und beiden Zervixlängenmessungen sowie deren Unterschied. Die ROC-Kurvenanalyse wies bis zu einer Falsch-Positiv-Rate von 20\% eine deutlich höhere Detektionsrate für vorzeitige Entbindungen durch die Kombination der Parameter auf. Bei einer Falsch-Positiv-Rate von 10\% - die einer Zervixlänge von jeweils 10 bzw. $9 \mathrm{~mm}$ bei der Erstbzw. Zweitmessung entspricht - lag die Detektionsrate bei der ersten Messung der Zervixlänge bei $17,6 \%$, bei der Zweitmessung bei $47,0 \%$ und, wenn der Unterschied zwischen den beiden Messwerten mitgerechnet wurde, bei 52,9\%.

Schlussfolgerung: Unsere Ergebnisse zeigen, dass es bei Frauen mit vorzeitigen Wehen nützlich sein kann, die Messung der Zervixlänge einige Tage nach der Erstmessung zu wiederholen und auf den Unterschied beider Messwerte zu achten. 


\section{Introduction}

\section{$\nabla$}

Prematurity remains one of the leading causes of perinatal morbidity and mortality as well as long term disability. Approximately $30 \%$ of preterm births are the result of idiopathic preterm labor. However, only about $10-15 \%$ of women presenting with symptoms of preterm labor deliver within the next two to seven days [1]. Therefore, it is not only critical to continue to search for effective therapies for preterm labor but also to improve our ability to identify patients that require treatment.

It has been shown that clinical examination, including digital examination of the cervix and uterine monitoring, fails to reliably identify the population of women that is destined to delivery within days of presentation. Therefore, a number of attempts have been made to develop tools that would help to distinguish between true and false preterm labor. The Health Technology Assessment (HTA) study from Honest et al. highlighted several approaches that appear to be useful in distinguishing patients that will deliver shortly after presentation and those that will not. The factors that they found to increase risk of premature delivery included short cervical length measured by transvaginal ultrasound and identification of endocervical funneling, absence of fetal breathing movements, elevated amniotic fluid interleukin-6 level, and elevated maternal serum C-reactive protein [2]. Other studies have identified cervical fetal fibronectin as a possibly useful predictor [3].

The most studied modality in this arena has been cervical assessment using transvaginal ultrasound [4-9]. This is due to the fact that transvaginal ultrasound is of no risk to the mother and the fetus, it is readily available and relatively easy to use, and the results are rapidly available at the bedside. In a meta-analysis of Sotiriadis et al. the authors tried to generate the most informative cervical length cut-off. They found that with a cut-off of $15 \mathrm{~mm}$, the detection rates for delivery within 48 hours, seven days, and before 34 weeks were $71 \%, 60 \%$ and $46 \%$, respectively for false positive rates of $13 \%, 10 \%$ and $6 \%$, respectively [10]. Hiersch et al. investigated whether cervical length cut-offs vary according to gestational age for delivery within 14 days after presentation [11]. They held the negative predictive value at $90 \%$ and found that the optimal cut-offs are 12, 14, 21 and $40 \mathrm{~mm}$ at 32-33, 30$31,27-29$ and 24 to 26 weeks' gestation, respectively. This study does suggest that adjusting cut-off according to gestational age may be appropriate. However, the cut-offs themselves are brought into question by the fact that the median cervical length at 24-26 weeks' gestation is only about $35 \mathrm{~mm}$ making their cutoff of $40 \mathrm{~mm}$ improbable [12].

There is ample evidence that transvaginal ultrasound assessment of the cervix and measurement of its length are helpful in predicting the risk of delivery in patients presenting with preterm contractions. However, much less is known about whether the predictive accuracy could be improved by obtaining serial measurements of the cervix after admission [13-16]. Intuitively, one would assume the cervix is more likely to progressively shorten in patients with true preterm labor as compared to patients with false preterm labor [13]. This could provide an additional way to establish an individualized risk of preterm birth. It could influence decisions regarding admission at a hospital that has the ability to provide neonatal intensive care and the length of admission. It could also influence decisions regarding tocolysis and corticosteroid administration to improve fetal lung maturity [17].
In this study, we examine the value of a repeat measurement some days after the first cervical length measurement done at the time of the patient's presentation with preterm contractions.

\section{Materials and Methods}

$\nabla$

\section{Inclusion criteria}

This is a retrospective study involving all women with singleton pregnancies who presented to the perinatal unit at the University Hospital of Tuebingen, Germany with painful and regular uterine contractions at 24 to $33+6$ weeks of gestation between 2011 and 2014. Women with ruptured membranes, history of conization of the cervix, those who had a cerclage placed in the current pregnancy, and those in active labor (defined by the presence of cervical dilatation of $\geq 3 \mathrm{~cm}$ ) were excluded.

\section{Data search}

The patients were searched for using our digital perinatology database. The following data were recorded: gestational age at presentation, gestational age at delivery, initial digital cervical assessment (cervical dilatation of $\geq 3 \mathrm{~cm}$ or not), cervical length measurements using transvaginal ultrasound at various points during the patient's hospitalization, maternal age and weight, gravidity and parity, white blood cell count, maternal serum Creactive protein levels, and presence or absence of bacterial vaginosis.

\section{Medical treatment and recording}

The perinatal unit at the University Hospital of Tuebingen is a tertiary referral center with about 3000 deliveries a year. At our institution, standard management of women suspected to be in preterm labor includes a transvaginal measurement of the cervical length by an experienced obstetrician, administration of tocolytics (in general oral nifedipine) for no more than 48 hours, administration of steroids and vaginal progesterone if the cervical length is $25 \mathrm{~mm}$ or less, and antibiotics if an ascending infection is suspected $[9,17-22]$. The cervical length is reassessed after two to five days after the initial assessment. The time interval between the two measurements depends on the patient's symptomatology. All available ultrasound data were entered into a digital database (Viewpoint, GE Healthcare, Munich, Germany). The outcome of the pregnancies was added as soon as it was available.

According to the German legislation and internal SOP, the retrospective analysis of data of our patients does require an approval of the local IRB. However, the local ethical committee was informed about the study (Project No. 447/2105R).

\section{Statistical analysis}

Univariate logistic regression analysis was used to examine significant covariates for a delivery within 14 days and before $34+0$ weeks of gestation. A ROC curve analysis was used to compare the first and second cervical length measurement and the additional assessment of the difference between both measurements (measurement 2 - measurement 1). A p-value of 0.05 was used as significance level. 


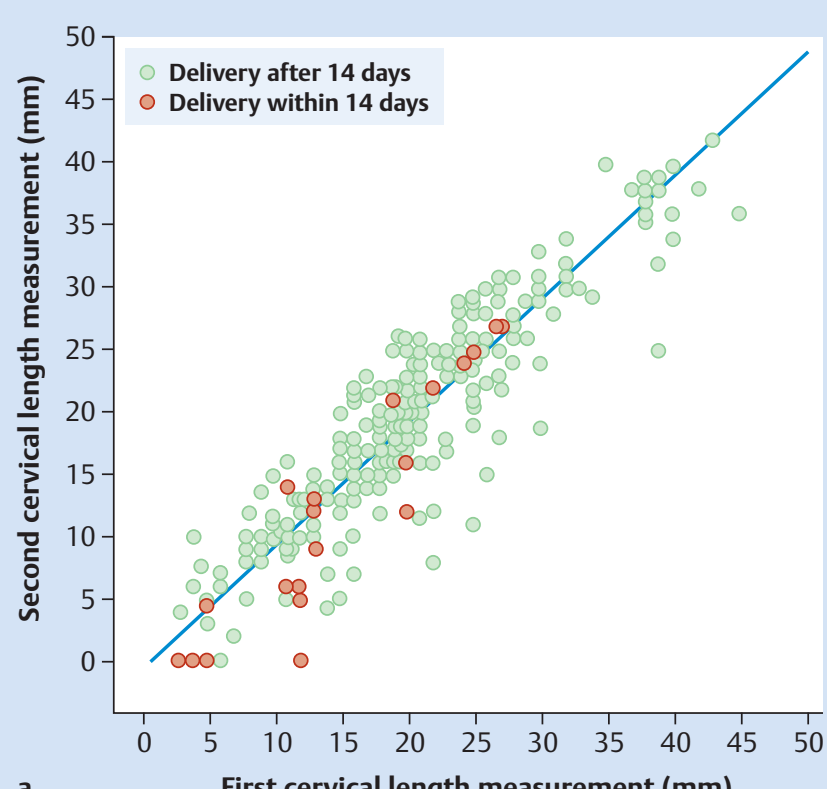

a

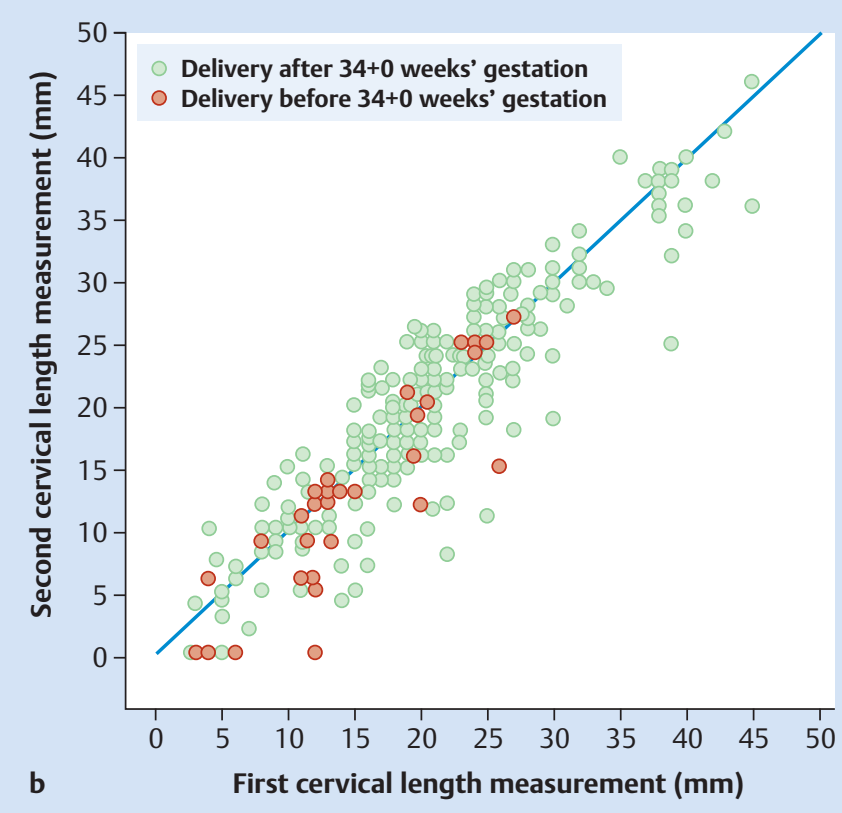

green dots represent the measurements in pregnancies where delivery occured after the respective time end points.
Fig. 1 First and second cervical length measurement in women with threatened preterm labor. In the left image, the red dots indicate delivery within 14 days, in the right image delivery before $34+0$ weeks' gestation. The

\section{Results}

\section{Description of the study population}

The study population involved 310 pregnancies. Mean maternal age and weight was $31.0( \pm 5.8)$ years and $70.2( \pm 13.2) \mathrm{kg}$, respectively. 306 (98.7\%) were Caucasians. 193 (62.3\%) were nulliparous and 27 (8.7\%) had a history of a preterm delivery before 37 weeks' gestation. Mean gestational age at the time of delivery was 37.5 ( \pm 3.1 ) weeks' gestation. In 6 (1.9\%), 32 (10.3\%) and 99 (31.9\%) of the cases, delivery occurred before 28,34 and 37 weeks' gestation, respectively. Delivery within 7 and 14 days of presentation occurred in 14 (4.5\%) and $22(7.1 \%)$ of the cases, respectively.
First and second measurement of the cervical length Mean gestational age at the time of the first examination was 29.0 ( \pm 3.0 ) weeks' gestation and mean cervical length was 19.4 $( \pm 8.6) \mathrm{mm}$. In 5 (1.6\%) cases, delivery occurred in less than $48 \mathrm{~h}$, so that a second cervical assessment could not be performed. In this group, mean cervical length was $3.2 \mathrm{~mm}$ (cervical length measurements $0.0,0.0,2.0,6.0$ and $8.0 \mathrm{~mm}$ ). These five cases were excluded from further analysis.

In the remaining 305 pregnancies - including 17 and 27 cases with preterm delivery within 14 days and before 34 weeks respectively - the cervical length was reassessed 3.6 days $( \pm 1.5)$ days later. The average cervical length at the time of the second measurement was $19.1( \pm 8.6) \mathrm{mm}(\bullet$ Fig. 1). Mean time interval

Table 1 Univariate logistic regression to predict preterm delivery within 14 days after the first examination and before 34 weeks' gestation.

\begin{tabular}{|c|c|c|c|c|c|c|}
\hline & \multicolumn{3}{|c|}{ Delivery within 14 days } & \multicolumn{3}{|c|}{ Delivery before 34 wks } \\
\hline & OR & $95 \% \mathrm{Cl}$ & $\mathbf{p}$ & OR & $95 \% \mathrm{Cl}$ & $\mathbf{p}$ \\
\hline Maternal age (yrs) & 0.990 & $0.910-1.077$ & 0.526 & 1.022 & $0.954-1.095$ & 0.535 \\
\hline Nullipara (n) & 1 & & & 1 & & \\
\hline Previous preterm delivery < 37 wks (n) & 3.459 & $0.986-12.137$ & 0.053 & 1.257 & $0.343-4.612$ & 0.730 \\
\hline Previous term but no preterm delivery ( $\mathrm{n}$ ) & 0.925 & $0.277-3.088$ & 0.899 & 0.848 & $0.339-2.125$ & 0.726 \\
\hline Weight $(\mathrm{kg})$ & 0.999 & $0.963-1.037$ & 0.959 & 1.001 & $0.972-1.031$ & 0.930 \\
\hline No cigarette smoking & 1 & & & & & \\
\hline Cigarette smoking & 1.004 & $0.126-8.025$ & 0.997 & 1.693 & $0.217-13.243$ & 0.616 \\
\hline C-reactive protein (mg/dl) & 1.133 & $0.775-1.655$ & 0.520 & 1.048 & $0.732-1.501$ & 0.796 \\
\hline White blood cell count $(\mathrm{n} / \mu \mathrm{l})$ & 1.000 & $1.000-1.000$ & 0.567 & 1.000 & $1.000-1.000$ & 0.804 \\
\hline No bacterial vaginosis & 1 & & & & & \\
\hline Bacterial vaginosis & 0.604 & $0.165-2.213$ & 0.447 & 0.748 & $0.243-2.301$ & 0.613 \\
\hline Gestational age at first Cx length measurement (wks) & 1.205 & $0.933-1.462$ & 0.060 & 0.887 & $0.779-1.010$ & 0.070 \\
\hline First Cx measurement (mm) & 0.900 & $0.837-0.968$ & $<0.005$ & 0.884 & $0.831-0.940$ & $<0.0001$ \\
\hline Gestational age at second Cx length meaurement (wks) & 1.040 & $0.966-1.120$ & 0.295 & 1.036 & $0.968-1.109$ & 0.313 \\
\hline Second Cx measurement (mm) & 0.868 & $0.808-0.933$ & $<0.0001$ & 0.865 & $0.815-0.919$ & $<0.0001$ \\
\hline Difference between first and second Cx measurement (mm) & 0.843 & $0.753-0.944$ & 0.003 & 0.887 & $0.805-0.978$ & 0.016 \\
\hline
\end{tabular}




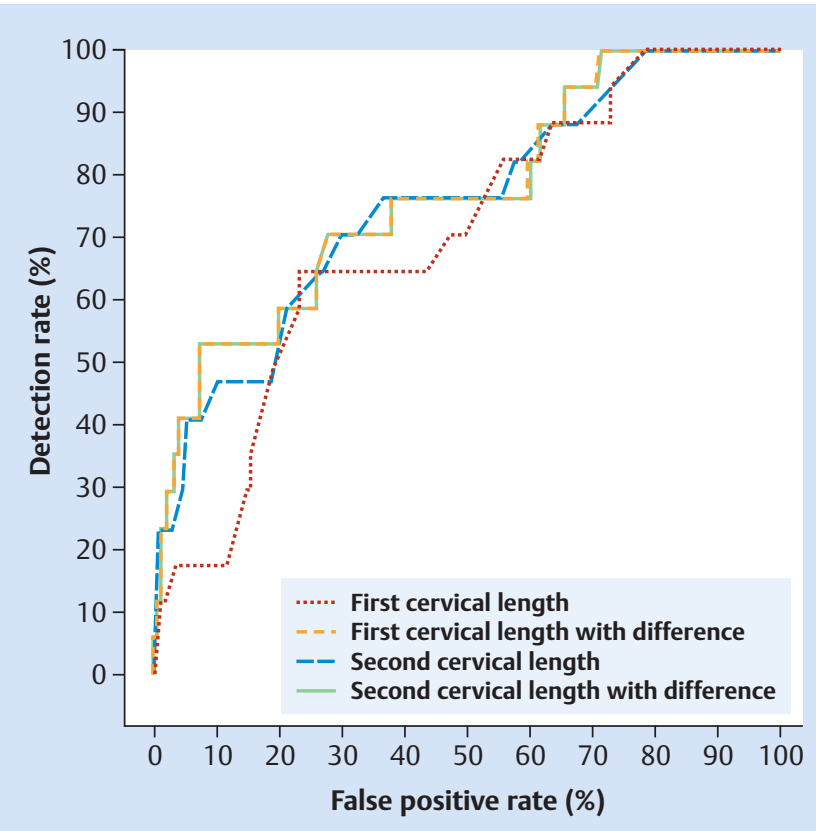

Fig. 2 ROC curve analysis for a delivery witihin 14 days. The models are based on the results shown in $\boldsymbol{Q}$ Table 2.

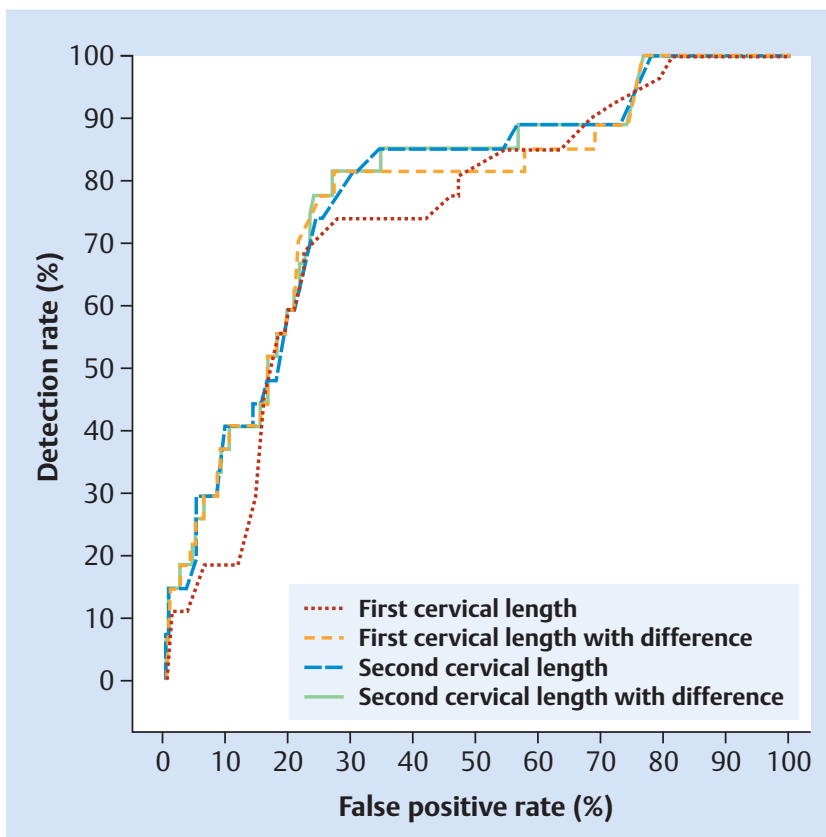

Fig. 3 ROC curve analysis for a delivery before 34 weeks' gestation. The models are based on the results shown in $\odot$ Table 2 . between both measurements did not correlate with the difference between the two measurements $(r=0,015 ; \mathrm{p}=0.799)$. Within the group of pregnancies that were delivered within the subsequent 14 days, the relationship between both measurements was cervix $2=0.842 \times$ cervix $1(p \leq 0.001, r=0.950)$ while it was cervix $2=0.971 \times$ cervix 1 in the group of women who remained undelivered $(\mathrm{p} \leq 0.001, \mathrm{r}=0.987)$.

\section{Comparison of different regression models}

Univariate logistic regression analysis indicates a significant correlation between delivery within 14 days of presentation as well as delivery before 34 weeks and both the first and second cervical length measurements as well as the difference between the two measurements ( Table 1 ).

- Fig. 2 contains ROC curves for the prediction of preterm birth within 14 days based on the first and second cervical length measurement with and without the difference between both measurements. The ROC curves are based on the multiple regression analysis as shown in Table 2 . It can be clearly seen that the addition of the difference between both measurements improves the model up to a false positive rate of $20 \%$. At a false positive rate of $10 \%$ - which corresponds to a first and second cervical length of 10 and $9 \mathrm{~mm}$ - the detection rate was $17.6 \%$ with the first cervical length measurement, $47.0 \%$ with the second and $52.9 \%$ if the difference between both measurements is added to the first or the second cervical length.

Similarly, the ROC curve analysis for the prediction of preterm birth before 34 weeks indicates that, up to a false positive rate of $20 \%$, the model based on the first cervical length measurement can be improved by taking into account the difference between the measurements ( $\nabla$ Fig. 3, Table 2). However, the model based on the second cervical length measurement does not improve with the addition of the difference between measurements. At a false positive rate of $10 \%$, the detection rate was $18.5 \%$ with the first cervical length measurement and $29.6 \%$ if the difference is added. The detection rate for the second measurement was also $29.6 \%$ and remained unchanged if the difference was added.

\section{Discussion}

$\nabla$

In this study we have shown that in women with threatened preterm labor a repeat measurement some days after the first cervical length measurement is helpful to predict the further course of the pregnancy. This is particularly the case in women with a cervical length of $10 \mathrm{~mm}$ or less.

Table 2 Logistic regression models in the prediction of preterm delivery within 14 days and before 34 weeks' gestation. In the first two models, either the first or the second cervical length measurement is used. In the third and fourth model the difference between both measurements is added to the first or second measurement.

\begin{tabular}{|l|llc|}
\hline & $\begin{array}{l}\text { Delivery within } \\
\text { 14 days }\end{array}$ & \multicolumn{2}{l}{$\begin{array}{l}\text { Delivery before } \\
\text { Estimate wks }\end{array}$} \\
\hline
\end{tabular}


Our data is consistent with results of several previously published studies that focused on the cervical length measurement in threatened preterm labor $[2,6,10,22,23]$. Most studies have used a cut-off of $15 \mathrm{~mm}$ [15]. Combined data from three studies that included 510 women with singleton pregnancies presenting in spontaneous preterm labour revealed that $49 \%$ of women with a cervical length $<15 \mathrm{~mm}$ delivered within seven days of presentation whereas only $1 \%$ did so if the cervical length was $\geq 15 \mathrm{~mm}$ [17]. In an HTA report by Honest et al., the authors demonstrated that the risk for delivery within seven days of presentation was increased 8.6 fold if the cervical length was $15 \mathrm{~mm}$ or less. Alfirevic et al. took this concept a step further [22]. They conducted a prospective multicenter study where women with preterm contractions were divided into two arms. In one arm, a transvaginal ultrasound cervical measurement was performed and if the cervical length was more than $15 \mathrm{~mm}$, they were managed expectantly without corticosteroids administration. Patients in the control arm were managed based on clinical assessment without sonographic cervical assessment [16]. The study was designed to evaluate the ability of the two approaches to identify women who will or will not deliver within seven days of presentation. The authors' focus was on the resultant appropriate versus unnecessary corticosteroid administration. They found that only $14 \%$ received an unnecessary course of corticosteroids in the study arm, which compared favourably with the control group where $90 \%$ received corticosteroids unnecessarily.

In women who do not deliver within the first 2-3 days of admission, a second cervical measurement or the change between the two measurements may improve our ability to predict the risk of subsequent delivery. In our study, the ROC curve analysis showed that up to a false positive rate of about $20 \%$ the second cervical length measurement performed better than the first one. Combination of the first or second cervical length measurement with the difference between both measurements was better than a single measurement alone. Sotiriadis et al. examined 122 women with preterm contractions and measured the cervix twice, at presentation and after 24 hours. They also found that the positive predictive value of the first cervical length measurement was increased by adding the difference between both measurements [15]. Rozenberg et al. examined 109 patients with threatened preterm labor at presentation and 48 hours later. They excluded women with a cervical length with more than $26 \mathrm{~mm}$ and women who delivered before a second measurement was performed [24]. In their study, the authors did not observe a benefit of adding the difference between the two measurements to the risk calculation based on the first measurement alone. Fox et al. measured cervical length in asymptomatic women between 16 and 28 weeks' gestation. If the cervical length was less than $25 \mathrm{~mm}$, they repeated the measurement three weeks later. They reported that decrease in cervical length correlated with earlier gestational age at delivery and with an increased proportion of women delivering before 37 weeks' gestation [23]. Moroz et al. reported on 2695 asymptomatic women with consecutive cervical length measurements after a median time interval of four weeks [16]. In the 250 women with a cervical length of less than $25 \mathrm{~mm}$, for every one millimeter shortening, the risk for preterm delivery increased by $3 \%$.

The main limitation of our study is the retrospective character. Furthermore, although our study population is reasonably large, there are still only 17 and 27 women with preterm delivery within 14 days and before 34 weeks. The fact that most published studies include a smaller number of symptomatic women points to the need to perform a multi-center study in order to show significant differences.

Generally, most studies focus on a time interval of seven days rather than 14 days. However, as the second measurement was 3.6 days later, we felt that the second measurement would be too close to the point of interest. In addition, in view of the further management, it is not only important to know how the management within the next few days should look like but also to plan a step further.

Our data confirms that in patients with preterm contractions, the management depends on the cervical length measurement. The first cervical length measurement at the time of presentation is essential in terms of the short term management. However, if the pregnancy carries on for the next few days, a second cervical assessment is useful. Especially in those cases with a short cervix of $10 \mathrm{~mm}$ or less, the detection rate of a preterm delivery within the following days can be substantially improved by the second measurement and by taking into account the difference between both measurements.

Assessment of the cervical length is crucial in women presenting with preterm contractions. Our results indicate that it is worth to repeat the measurement some days later and to take into account the difference between both measurements.

\section{Acknowledgements \\ $\nabla$}

The study was accredited by the Arbeitsgemeinschaft MaternoFetale Medizin.

\section{Conflict of Interest}

$\nabla$

None.

\section{References}

1 Kenyon SL, Taylor DJ, Tarnow-Mordi W. Broad-spectrum antibiotics for spontaneous preterm labour: the ORACLE II randomised trial. Lancet 2001; 357: 989-994

2 Honest H, Forbes CA, Durée KH et al. Screening to prevent spontaneous preterm birth: systematic reviews of accuracy and effectiveness literature with economic modelling. Health Technol Assess 2009; 13: 1-627

3 Deshpande SN, van Asselt ADI, Tomini F et al. Rapid fetal fibronectin testing to predict preterm birth in women with symptoms of premature labour: a systematic review and cost analysis. Health Technol Assess 2013; 17: 1-138

4 Tsoi E, Akmal S, Rane S et al. Ultrasound assessment of cervical length in threatened preterm labor. Ultrasound Obstet Gynecol 2003; 21: 552555

5 Tsoi E, Akmal S, Geerts L et al. Sonographic measurement of cervical length and fetal fibronectin testing in threatened preterm labor. Ultrasound Obstet Gynecol 2006; 27: 368-372

6 Wulff $C B$, Ekelund CK, Hedegaard $M$ et al. Can a 15-mm cervical length cutoff discriminate between low and high risk of preterm delivery in women with threatened preterm labor? Fetal Diagn Ther 2011; 29: 216-223

7 Palacio M, Sanin-Blair J, Sánchez $M$ et al. The use of a variable cut-off value of cervical length in women admitted for preterm labor before and after 32 weeks. Ultrasound Obstet Gynecol 2007; 29: 421-426

8 Fuchs IB, Henrich W, Osthues K et al. Sonographic cervical length in singleton pregnancies with intact membranes presenting with threatened preterm labor. Ultrasound Obstet Gynecol 2004; 24: 554-557

9 Kagan KO, Sonek J. How to measure cervical length. Ultrasound Obstet Gynecology 2015; 45: 358-362 
10 Sotiriadis A, Papatheodorou S, Kavvadias A et al. Transvaginal cervical length measurement for prediction of preterm birth in women with threatened preterm labor: a meta-analysis. Ultrasound Obstet Gynecol 2010; 35: 54-64

11 Hiersch L, Yogev Y, Domniz N et al. The role of cervical length in women with threatened preterm labor: is it a valid predictor at any gestational age? Am J Obstet Gynecol 2014; 211: 532.e1-532.e9

12 To MS, Skentou CA, Royston P et al. Prediction of patient-specific risk of early preterm delivery using maternal history and sonographic measurement of cervical length: a population-based prospective study. Ultrasound Obstet Gynecol 2006; 27: 362-367

13 Iams JD. Cervical length-time to report the rate of change? Am J Obstet Gynecol 2014; 211: 443

14 Naim A, Haberman S, Burgess T et al. Changes in cervical length and the risk of preterm labor. Am J Obstet Gynecol 2002; 186: 887-889

15 Sotiriadis A, Kavvadias A, Papatheodorou S et al. The value of serial cervical length measurements for the prediction of threatened preterm labour. Eur J Obstet Gynecol Reprod Biol 2010; 148: 17-20

16 Moroz LA, Simhan HN. Rate of sonographic cervical shortening and the risk of spontaneous preterm birth. Am J Obstet Gynecol 2012; 206: 234.e1-234.e5
17 Kagan KO, To M, Tsoi E et al. Preterm birth: the value of sonographic measurement of cervical length. BJOG 2006; 113 (Suppl. 3): 52-56

18 Flenady V, Wojcieszek AM, Papatsonis DNM et al. Calcium channel blockers for inhibiting preterm labour and birth. Cochrane Database Syst Rev 2014; 6: CD002255

19 Roberts D, Dalziel S. Antenatal corticosteroids for accelerating fetal lung maturation for women at risk of preterm birth. Cochrane Database Syst Rev 2006; 3: CD004454

20 Bomba-Opon DA, Kosinska-Kaczynska K, Kosinski P et al. Vaginal progesterone after tocolytic therapy in threatened preterm labor. J Matern Fetal Neonatal Med 2012; 25: 1156-1159

21 Areia A, Fonseca E, Moura P. Progesterone use after successful treatment of threatened pre-term delivery. J Obstet Gynaecol 2013; 33: 678-681

22 Alfirevic Z, Allen-Coward H, Molina F et al. Targeted therapy for threatened preterm labor based on sonographic measurement of the cervical length: a randomized controlled trial. Ultrasound Obstet Gynecol 2007; 29: 47-50

23 Fox NS, Jean-Pierre C, Predanic $M$ et al. Short cervix: is a follow-up measurement useful? Ultrasound Obstet Gynecol 2007; 29: 44-46

24 Rozenberg P, Rudant J, Chevret $S$ et al. Repeat measurement of cervical length after successful tocolysis. Obstet Gynecol 2004; 104: 995-999 